\title{
PAISAJE, TERRITORIO Y SOCIEDAD CIVIL
}

\author{
Landscape, Territory and Civil Society
}

Prof. Dr. Joan Nogué

Universitat de Girona

Luís Companys, 27, 2º $1^{\text {a }} 17820$ - Banyoles (SPAIN)

Tel: 972418715 - joan.nogue@udg.edu

$a \propto a \cap a$

\section{Resumo}

Nunca se falou tanto sobre paisagem. Ela entrou no debate territorial. No entanto, há uma razão raramente considerada e a qual, do meu ponto de vista, é importante: o relevante papel que ela tem e sempre teve na formação e consolidação de identidades territoriais. A paisagem atua de forma catalisadora, como elemento central do crescente conflito de caráter territorial e ambiental tangível em nossa sociedade. Diríamos certamente, a sociedade civil reage, produzindo clima de opinião que se conecta perfeitamente com uma corrente de fundo reivindicadora de uma nova cultura do território. A tudo isso irei me referir.

Palavras-chave: Paisagem, território, identidades territoriais

\begin{abstract}
In present times the concept of landscape has been widely discussed.The landscape has entered in the territorial debate. However, from my point of view, there is an important and rarely considered reason: the relevant role that landscape has and always had in the formation and consolidation of territorial identities. The landscape acts as a catalyst and as a central element of growing conflict of territorial and environmental nature that is tangible in our society. We would say that the civil society reacts, creating atmosphere of opinion that connects perfectly with a power that reclaims a new culture of the territory. To all this I will refer.
\end{abstract}

Key words: Landscape, territory, territorial identities.

\section{Resumen}

Nunca como ahora se había hablado tanto de paisaje. El paisaje haya entrado en el debate territorial, sin embargo, hay una razón que pocas veces se considera y que, desde mi punto de vista, es importante: el papel relevante que el paisaje tiene y ha tenido siempre en la formación y consolidación de identidades territoriales. El paisaje actúe a modo de catalizador, de elemento vertebrador de la creciente conflictividad de carácter territorial y ambiental palpable en nuestra sociedad. Diríamos de ánimo, la sociedad civil reacciona, generando un estado de opinión que conecta perfectamente con una corriente de fondo que reclama una nueva cultura del territorio. A todo ello voy a referirme.

Palabras claave: Paisage, territorio, identidade territorial. 


\section{INTRODUÇÃO}

Nunca como ahora se había hablado tanto de paisaje, ya sea en los ámbitos especializados o en los grandes medios de comunicación. Hay varias razones que explican este fenómeno: la progresiva concienciación ambiental de los últimos veinte años, que ha beneficiado indirectamente al paisaje; la extensión galopante de la ciudad dispersa vinculada al auge extraordinario del sector de la construcción, que, por primera vez en la historia, ha sido capaz de transformar la fisonomía de miles de hectáreas en un cortísimo espacio de tiempo; la implantación sobre el territorio de infraestructuras de todo tipo, algunas de ellas antipáticas y molestas a los ojos de los ciudadanos que ya vivían en esos enclaves; o, por poner un último ejemplo, una mayor sensibilidad estética por parte de determinados grupos y colectivos capaces de crear opinión en los medios de comunicación. Todas estas razones son relevantes y explican, en mi opinión, que el paisaje haya entrado de lleno - y ya para no irse - en el debate territorial. Sin embargo, hay otra razón que pocas veces se considera y que, desde mi punto de vista, es tanto o más importante que las anteriores: me refiero al papel relevante que el paisaje tiene y ha tenido siempre en la formación y consolidación de identidades territoriales. Esto es lo que explica que el paisaje actúe a modo de catalizador, de elemento vertebrador de la creciente conflictividad de carácter territorial y ambiental palpable en nuestra sociedad. Ante la pérdida de la idiosincrasia territorial local debida a procesos no consensuados y casi siempre mal explicados, la sociedad civil reacciona de manera cada vez más indignada, generando un estado de opinión -casi diríamos de ánimo- que, a su vez, conecta perfectamente con una corriente de fondo que reclama, desde hace años, una nueva cultura del territorio. A todo ello voy a referirme en las páginas que siguen.

\section{PAISAJE, SENTIDO DE LUGAR E IDENTIDAD TERRITORIAL}

En general, la gente se siente parte de un paisaje, con el que establece múltiples y profundas complicidades. Este sentimiento es legítimo, ancestral y universal y, si bien es verdad que la tensión dialéctica entre lo local y lo global generada por lo que habitualmente entendemos por globalización está afectando muchísimo a los lugares, también lo es que, en buena medida, seguimos actuando como una cultura territorializada y, en ella, el paisaje ejerce un rol social y cultural destacado.

La tradición académica más sobresaliente de los últimos dos siglos no ha obviado esta realidad, sino todo lo contrario. Lo sabían bien a finales del siglo XIX y principios del XX las más importantes escuelas geográficas europeas, aun influidas en muchos aspectos por el legado de Humboldt. El acercamiento al paisaje de este autor responde a una sensibilidad de corte romántico que aspira a aunar "explicación y comprensión, razón y sentimiento, arte y ciencia", en palabras de Nicolás Ortega Cantero (2004, p. 24). El paisajismo geográfico que inaugura Humboldt combina de manera magistral las dimensiones naturales y culturales del mismo. Unos años más tarde, en la Landschaftgeographie alemana se dará una clara asociación de ideas entre paisaje y región, dos conceptos utilizados casi como sinónimos. Lo mismo vale para la rica tradición geográfica francesa de la época, la denominada escuela regional francesa o escuela vidaliana, en honor a su fundador, Paul Vidal de la Blache, tan influyente en estas latitudes ibéricas.

Para esta escuela, el paisaje es la fisonomía característica que nos revela una porción del espacio concreta - una región- y la distingue de otras. Es en la región -en el lugar, si se quiere- donde cristalizan las relaciones naturalezacultura. La interpenetración naturaleza-cultura daría a la región un carácter distintivo que la haría única, irrepetible y que se visualizaría, se materializaría a través de un paisaje. La idea, la metáfora de que el paisaje es el rostro del territorio nace en este momento y sigue hoy vigente.

El paisaje en la tradición geográfica francesa es, sin duda, un concepto fundamental y su estudio precisará no sólo de una sólida formación científica, sino también de una gran base humanista. Geógrafos como Jean Brunhes, Albert Demangeon, Max Sorre, Roger Dion, Camille Vallaux o, en 
nuestro país, Manuel de Terán o Pau Vila, entre muchos otros, son, sobre todo, hombres cultísimos y de una especial sensibilidad, además de sólidos científicos. Escribían - y describían - de una manera magistral, con un esperit de finesse al alcance de muy pocos hombres de ciencia. Entendían que la esencia de un paisaje, su carácter y personalidad, no podía ser transmitida sin un dominio absoluto del lenguaje, lo que ha convertido algunas de sus obras en auténticos clásicos, en verdaderas obras de arte. En este sentido, Anne Buttimer (1980) llega a calificar el Tableau de la géographie de la France, de Paul Vidal de la Blache, de Mona Lisa de la geografía moderna.

Un espíritu parecido, aunque en las antípodas en muchos otros sentidos, compartían los geógrafos anarquistas de la época, coetáneos de esta tradición geográfica francesa, en concreto Elisée Reclus y Piotr Kropotkin, dos de los más conocidos y hoy felizmente recuperados gracias, en buena medida, al interés que su obra despertó muchas décadas después entre algunos geógrafos radicales de la década de 1970. Viajeros empedernidos, su geografía de alto contenido social y base anarquista hubiera sido inconcebible sin este contacto directo con la realidad al que aquí estamos aludiendo. Elisée Reclus era, por cierto, un geógrafo de una especial sensibilidad en relación con el paisaje porque en sus textos no sólo reacciona indignado contra las injusticias sociales, sino también contra aquellos que osaban romper los íntimos lazos entre el paisaje y el que lo habita, avanzándose al discurso ecologista y estético de nuestros días. Decía así (COLECTIVO DE GEÓGRAFOS, 1980):

"El hombre de mañana, elevado a la comprensión de la belleza, sabrá... no colocar su morada de modo que se rompan las líneas, que se borren brutalmente el color y los matices: sentirá vergüenza en disminuir y alegría por aumentar la belleza de cuanto le rodee. (p.274)...y (sentirá) una impresión de verdadera repugnancia cuando arquitectos insolentes, pagados por hosteleros sin pudor, edifiquen enormes guaridas, bloques rectangulares donde se hallan inscritos los rectángulos de mil ventanas y en los que sobresalen cien humeantes chimeneas frente a glaciares, montañas nevadas, cascadas o frente al Océano" (p.275).

Y si cruzamos el Atlántico y nos situamos en América del Norte nos encontraremos con una perspectiva parecida de la mano de Carl O. Sauer, geógrafo que en los años 1920 acuñó el concepto de paisaje cultural, aún hoy vigente en muchos sentidos. La rica tradición norteamericana de estudios del paisaje en tanto que expresión de un sentido de lugar debe muchísimo a la obra de los geógrafos culturales discípulos de Sauer. Figuras del calibre de un John Brinckerhoff Jackson, fundador de la revista Landscape, o de un Yi-Fu Tuan, uno de los padres de la denominada geografía humanística, no se entienden sin el legado de Sauer. Y todos ellos, sin excepción, vincularon paisaje y sentido de lugar.

Así pues, la gente se siente parte de un paisaje, ingrediente fundamental de su sentido de lugar. A pesar de que los lugares - y sus paisajes - han acusado el impacto de las telecomunicaciones, de la mayor velocidad de los sistemas de transporte, de la mundialización de los mercados, de la estandarización de las modas, de los productos y de los hábitos de consumo, la inmensa mayoría de lugares siguen conservando su carácter y, en ellos, la gente no ha perdido aún - o no del todo- su sentido de lugar. Se resiste a perderlo, no se resigna a que le eliminen de un plumazo la idiosincrasia de sus paisajes y, en el fondo, la conflictividad territorial hoy existente es una prueba de ello, como veremos más adelante. El paisaje sigue desempeñando un papel fundamental no sólo en el proceso de creación de identidades territoriales, a todas las escalas, sino también en su mantenimiento y consolidación. Y esto es así porque, en el fondo, al hablar de paisaje estamos hablando de una porción de la superficie terrestre que ha sido modelada, percibida e interiorizada a lo largo de décadas o de siglos por las sociedades que viven en ese entorno. El paisaje está lleno de lugares que encarnan la experiencia y las aspiraciones de la gente; lugares que se convierten en centros de significado, en símbolos que expresan pensamientos, ideas y emociones varias. El paisaje no sólo nos presenta el mundo tal como es, sino que es también, de alguna manera, una construcción de este mundo, una forma de verlo. El paisaje es, en buena medida, una construcción social y cultu- 
ral, siempre anclado - eso sí - en un substrato material, físico. El paisaje es, a la vez, una realidad física y la representación que culturalmente nos hacemos de ella; la fisonomía externa y visible de una determinada porción de la superficie terrestre y la percepción individual y social que genera; un tangible geográfico y su interpretación intangible. Es, a la vez, el significante y el significado, el continente y el contenido, la realidad y la ficción. Escritores, poetas y pensadores han entendido perfectamente esta significación dual del paisaje, al que han visto, a menudo, como el espejo del alma en el territorio. El filósofo y escritor chino Lin Yutang (1895-1976), uno de los principales introductores de la filosofía oriental en el mundo occidental, lo resumía con este simple aforismo: "La mitad de la belleza depende del paisaje y la otra mitad de quien lo contempla". Pocos años antes, Henry-Fréderic Amiel, pensador francés, había escrito que "el paisaje es un estado del alma", algo que los pintores románticos, como Caspar Friedrich, intentaban trasladar a sus cuadros.

\section{LAS TRANSFORMACIONES TERRITORIALES Y SU IMPACTO PAISAJÍSTICO}

Si aceptamos que el paisaje es el resultado de una transformación colectiva de la naturaleza, la proyección cultural de una sociedad en un espacio determinado, debemos aceptar su intrínseco carácter dinámico.

Grosso modo, la rica tradición académica apuntada más arriba aceptaba sin reparos que, en efecto, los paisajes son, por definición, dinámicos, algo que, hoy día, los estudiosos del paisaje dan por sentado, sea cual sea su perspectiva disciplinar. Las sociedades humanas, a través de su cultura, transforman los originarios paisajes naturales en paisajes culturales, caracterizados no sólo por una determinada materialidad, sino también por la translación al propio paisaje de sus valores, de sus sentimientos. El paisaje es cultura y, precisamente por ello, es algo vivo, dinámico y en continua transformación, en continua mutación.

La cuestión - convertida en problema en el contexto que aquí nos ocupa - no reside tanto en la transformación, per se, de los paisajes como resultado de las correspondientes dinámicas territoriales, sino en el carácter e intensidad de estas transformaciones. No hay duda de que, a lo largo de las últimas décadas y en un periodo muy corto de tiempo, hemos modificado el territorio como nunca antes habíamos sido capaces de hacerlo y, en general, ello no ha redundado en una mejora de la calidad del paisaje, sino más bien lo contrario. Hemos asistido a un empobrecimiento paisajístico que ha arrojado por la borda buena parte de la idiosincrasia de muchos de nuestros paisajes. Durante este periodo, la dispersión del espacio construido ha provocado una fragmentación territorial de consecuencias ambientales y paisajísticas preocupantes, agravadas por el abandono de la actividad agraria. El crecimiento urbanístico desorganizado, espacialmente incoherente, desordenado y desligado de los asentamientos urbanos tradicionales ha destruido la lógica territorial de muchos rincones del país.

Ello, junto con la implantación de determinados equipamientos e infraestructuras pesadas y mal diseñadas, así como la generalización de una arquitectura de baja calidad estética - en especial en algunas áreas turísticas -, ha generado unos paisajes mediocres, dominados cada vez más por la homogeneización y la trivialización. La uniformización y la falta de calidad y

originalidad de los tipos de construcciones mayoritarias han producido en muchos lugares un paisaje insensible, aburrido y sin el menor interés, sobre todo en los espacios suburbanos, fronterizos, de transición, en los que la sensación de caos y de desconcierto se vive con más intensidad. En los últimos decenios hemos asistido, en efecto, a la emergencia de territorios sin discurso y de paisajes sin imaginario, precisamente en un país con una enorme y variada riqueza paisajística, lo cual es doblemente grave.

Se mire por donde se mire, nunca habíamos sido capaces de consumir tanto territorio en tan pocos años y nunca habíamos transformado este territorio a tal rapidez. Cuando el paisaje se transforma con esta intensidad y a esta velocidad, se producen dos efectos perversos. 
Por una parte, el riesgo de destrucción de dicho paisaje es muy alto, puesto que pueden eliminarse de un plumazo, como así ha sucedido en muchos casos, aquellos rasgos que le han dado personalidad y continuidad histórica.

Cuando esto sucede, estamos hablando pura y llanamente de 'destrucción' del paisaje y no de evolución gradual y pausada del mismo. Es muy difícil alterar, modificar, intervenir, sin destruir, a la velocidad e intensidad imperantes en los últimos años. El otro efecto es de carácter más bien psicológico. Siguiendo a Eugenio Turri, "las modificaciones del paisaje en el pasado solían ser lentas, pacientes, al ritmo de la intervención humana, prolongadas en el tiempo y fácilmente absorbibles por la naturaleza de los seres humanos: el elemento nuevo se insería gradualmente en el cuadro psicológico de la gente. Pero cuando esta inserción es rápida, como en los últimos años, la absorción se hace mucho más difícil” (1979, p.36). Poco más podemos añadir a las sabias palabras de Eugenio Turri.

Los procesos descritos anteriormente han provocado que los lugares estén perdiendo sus límites. Hasta hace muy pocas décadas, los distintos usos del suelo tenían unos límites relativamente nítidos $\mathrm{y}$, sin ir más lejos, se podía percibir sin demasiada dificultad dónde terminaba la ciudad y dónde empezaba el campo. En la actualidad, la estructura y morfología del paisaje de la mayor parte del territorio (también el rural, aunque menos) se caracteriza por una alta fragmentación. La zonificación característica del paisaje tradicional se ha transformado radicalmente y ha derivado hacia una gran dispersión de usos y de cubiertas del suelo. La antigua zonificación se ha difuminado, se ha perdido la claridad en la delimitación zonal, la compacidad se ha roto y ha conseguido imponerse un paisaje mucho más complejo, un paisaje de transición, un paisaje híbrido, cuya lógica discursiva es de más difícil aprehensión, hasta el punto que nos obliga a preguntarnos a menudo si el genius loci correspondiente no ha huido de él; si no habremos cambiado realmente de lugar, de país, parafraseando la excelente obra de David Lowenthal (1998), El pasado es un país extraño. De hecho, cuando se observan con detenimiento los fotogramas del famoso 'vuelo americano' de 1956, uno tiene realmente la sensación de estar contemplando otro territorio, de habernos equivocado de país.

Los procesos a los que aquí aludimos han generado unos paisajes de frontera difusa, a los que algunos teóricos anglosajones ya han bautizado como sprawlscapes o paisajes de la dispersión; paisajes que ocupan amplias extensiones de territorio en forma de manchas de aceite y que transmiten una nueva concepción del espacio y del tiempo. La legibilidad semiótica de estos paisajes contemporáneos sometidos a intensas transformaciones es muy compleja. No es nada fácil la descodificación de sus símbolos. La legibilidad de estos nuevos paisajes es más complicada que la propia del paisaje urbano compacto, aquella que aprendimos de la semiología urbana.

En su ya clásico tratado sobre la imagen de la ciudad, Kevin Lynch (1960) resaltaba cinco categorías esenciales para la lectura del paisaje urbano convencional: señales, nodos, senderos, umbrales y áreas homogéneas. ¿Qué categorías, qué claves interpretativas permitirían leer hoy el paisaje de la dispersión, el sprawlscape? Seguramente existen, y más pensadas para ser leídas en coche que no a pie, pero son, sin duda, más efímeras que las propuestas por Kevin Lynch, y de más difícil legibilidad. No es fácil integrar en una lógica discursiva clara y comprensible los territorios fracturados y desdibujados de estos paisajes de frontera, que alternan sin solución de continuidad adosados, terrenos intersticiales yermos y abandonados, polígonos industriales o simulacros de polígonos industriales, viviendas dispersas, edificaciones efímeras, vertederos incontrolados, cementerios de coches, almacenes precarios, líneas de alta tensión, antenas de telefonía móvil, carteles publicitarios (o sus restos), descampados intermitentes, ... en fin, un desorden general, que genera en el ciudadano una desagradable sensación de confusión, de insensibilidad, de desconcierto. Los territorios parecen no poseer discurso y de los paisajes parece haberse esfumado su imaginario cuando su legibilidad se vuelve extremadamente compleja, tan compleja que se acerca a la invisibilidad.

Además de las transformaciones físicas de los paisajes contemporáneos propiamente dichas y ya expuestas, el desconcierto - y descontento - social ante las mismas se ve incrementado por 
otro fenómeno no muy estudiado hasta el presente. Me refiero a la creciente sensación de divorcio entre los paisajes que imaginamos y los que vivimos (NOGUÉ, 2006). En efecto, el abismo entre los paisajes contemplados cotidianamente y los paisajes de referencia transmitidos de generación en generación a través de vías tan diversas como la pintura de paisajes, la fotografía, los libros de texto o los medios de comunicación es cada vez mayor. Asistimos a una crisis de representación entre unos paisajes de referencia que en algunos casos se han convertido en auténticos arquetipos y los paisajes reales, diarios, que, para una gran parte de la población, son precisamente los paisajes fuertemente transformados que perciben cotidianamente. La contemplación del paisaje real contemporáneo está teñida a menudo de este paisaje arquetípico ya aludido, un paisaje que se habría generado en el marco de un proceso de 'socialización' del paisaje perfectamente contextualizable, es decir en un lugar y en un momento determinados, impulsado por una élite cultural, literaria y artística procedente de un determinado grupo social, que elaboraría una metáfora y la difundiría al conjunto de la sociedad.

Estaría por ver, claro está, si la imagen seleccionada era la mayoritaria y cuáles se dejaron de lado, porque debemos admitir que todas ellas, en tanto que representaciones sociales del paisaje, tienen - tenían - la misma legitimidad social. Sea como fuere, lo cierto es que se produce una socialización de un paisaje arquetípico que nos ha llegado hasta hoy a través de muchas y diversas imágenes que han creado un imaginario colectivo, compartido y socialmente aceptado. El arquetipo paisajístico inglés, por ejemplo, sigue siendo muy potente y, en él, el pasado tiene un peso enorme.

Es conocida la habilidad típicamente inglesa para saber mirar el paisaje a través de sus asociaciones con el pasado y para evaluar los lugares en función de sus conexiones con la historia. Un paisaje bucólico, pintoresco, ordenado, humanizado, verde y con bosques caducifolios conforma el ideal de belleza paisajística para la mayoría de los ingleses. El paisaje es aquí concebido casi como una vieja antigüedad. David Matless (1998), en su libro Landscape and Englishness, va más allá y muestra incluso cómo el paisaje típicamente inglés es un elemento fundamental de la 'anglicidad', es decir la esencia de lo inglés. En Francia, Yves Luginbhul (1989), Augustin Berque (1990 y 1995), Alain Roger (1997) y sobre todo Pierre Nora (1984) en el libro colectivo Les Lieux de mémoire, entre muchos otros y cada uno a su manera, también apuntan en la misma dirección.

El caso de Cataluña es paradigmático al respecto (NOGUÉ, 2005). La sociedad catalana y, en concreto, el nacionalismo catalán, ha generado y convivido en el último siglo y medio con varios arquetipos paisajísticos, básicamente con dos: el de la Cataluña verde, húmeda, pirenaica, de montaña, impulsado por la Renaixença y recogido en buena parte por el modernismo, y el de la Cataluña mediterránea, marítima, soleada e intensamente humanizada (por no decir urbanizada), generado por el noucentisme. Dos arquetipos que se han ido alternando, en algunas ocasiones complementándose y en otras excluyéndose. De los dos, y si nos situamos en el ámbito estrictamente nacionalista, ha salido victorioso el primero.

Ahora bien, la hegemonía de este arquetipo paisajístico por parte del discurso nacionalista ha tenido también efectos geopolíticos indeseables, al infravalorar el paisaje de la Cataluña no asociada al patriotismo, la que no fue escenario de las gestas medievales y sus mitos épicos: la Cataluña seca, los territorios del sur del país. Así, el área meridional del país - supuestamente sin valor identitario - ha sido la receptora de las únicas centrales nucleares y del mayor complejo petroquímico; ha padecido la sequía a pesar de estar atravesada por el río más caudaloso de la Península; ha estado a punto de sufrir las consecuencias medioambientales de uno de los trasvases más polémicos del continente europeo y tendrá que acoger al $80 \%$ de los parques eólicos previstos, con sus correspondientes impactos paisajísticos.

Podríamos seguir exponiendo otros muchos casos parecidos al inglés, al francés o al catalán y en todos ellos asistiríamos al mismo proceso: creación de arquetipos en un momento y lugar concretos, intensa transformación de los paisajes contemporáneos, creciente abismo entre estos paisajes y aquellos arquetipos, emergencia de la mencionada crisis de representación. Ahora bien, 
parece evidente que si dicha crisis de representación ha salido a la luz es debido a que, más allá de los núcleos urbanos compactos, no hemos sido capaces de dotar de identidad - la que sea - a unos paisajes caracterizados en buena medida por su mediocridad y banalidad. No hemos conseguido crear nuevos arquetipos paisajísticos o, al menos, nuevos paisajes dotados de fuerte personalidad e intensa carga simbólica, en especial en los entornos más degradados y fracturados. Nos hemos atrevido a proponer intervenciones paisajísticas que no han ido mucho más allá de la pura jardinería, porque no estaban soportadas por un nuevo discurso territorial y, por lo tanto, no nos hemos atrevido a experimentar nuevos usos y cánones estéticos. Puede que haya faltado imaginación, creatividad y sentido del lugar, pero lo cierto es que no hemos sido capaces de generar nuevos paisajes con los que la gente pueda identificarse, nuevos paisajes de referencia; no hemos sido capaces, en definitiva, de reinventar una dramaturgia del paisaje, siguiendo aquí a Paul Virilio.

Las transformaciones territoriales descritas hasta el momento y sus impactos paisajísticos, junto con la ya mencionada crisis de representación, están en la base de la reacción suscitada en muchos sectores de la sociedad civil. La conflictividad territorial contemporánea refleja en buena medida el miedo a la pérdida del propio sentido de lugar. Y es precisamente entonces cuando el paisaje actúa a modo de catalizador, de elemento vertebrador de esta creciente conflictividad de carácter territorial y ambiental palpable en nuestra sociedad. Ante la pérdida de la idiosincrasia territorial local debida a procesos no consensuados y casi siempre mal explicados, la sociedad civil reacciona de manera cada vez más indignada, generando un estado de opinión - casi diríamos de ánimo - que, a su vez, conecta perfectamente con una corriente de fondo que reclama, desde hace años, una nueva cultura del territorio.

\section{LA REACCIÓN DE LA SOCIEDAD CIVIL}

La proliferación de plataformas en defensa del territorio es un fenómeno social extraordinariamente interesante, que, además, se da en unos momentos de escasa participación en las estructuras políticas convencionales y que va mucho más allá de la explosión ecologista y minoritaria de finales de los setenta y principios de los ochenta, puesto que ahora agrupa a colectivos nada minoritarios y a personas de la más variada procedencia. Dada su relevancia, sorprende que a estas alturas aún no se haya estudiado en profundidad, si exceptuamos algunas recientes aproximaciones al mismo (ALFAMA ET AL., 2007; GARCIA 2003; NEL.LO 2003).

Más allá de las dinámicas propias e intransferibles de todos los conflictos territoriales hoy existentes y de las correspondientes plataformas cívicas que han originado, lo cierto es que la extensión de este tipo de conflictividad obedece a una serie de factores comunes. En primer lugar y como ya hemos avanzado más arriba, la creciente importancia del lugar y de las identidades territoriales en un contexto de globalización galopante, que ha producido una tensión dialéctica entre lo local y lo global no siempre resuelta de forma satisfactoria. En segundo lugar, una crisis de confianza en las instituciones y en los sistemas de representación política convencionales, al no encontrar en ellos ni la respuesta esperada ni la adecuada. Finalmente, unas políticas territoriales (y también ambientales) a menudo mal diseñadas y, sobre todo, mal explicadas. Son habituales las descalificaciones de este tipo de movimientos y de plataformas, a las que se acusa desde el establishment de insolidaridad territorial y de responder a un cierto romanticismo infantil y a una cultura del no incapaz de asumir con responsabilidad los inevitables costes que conlleva el progreso. Mi opinión personal es que las cosas son bastante más complicadas.

Estos nuevos movimientos sociales tienen mucho que ver con los procesos de mundialización y sus incertidumbres, así como con la sensación de inseguridad e impotencia que generan en el individuo. Asistimos, en efecto, a una especie de retorno al lugar, expresión que no quiere indicar nada más que la creciente importancia que tiene el lugar y su identidad en el mundo contemporáneo. Aunque el espacio y el tiempo se hayan comprimido, las distancias se hayan relativizado y 
las barreras espaciales se hayan suavizado, los lugares no sólo no han perdido importancia, sino que han aumentado su influencia y su peso específico en los ámbitos económico, político, social y cultural. Bajo unas condiciones de máxima flexibilidad general y de incremento de la capacidad de movilidad por todo el territorio, tanto los sectores económicos como los agentes políticos y sociales no tienen más remedio que prestar más atención que nunca a las particularidades del lugar. Las pequeñas -o no tan pequeñas- diferencias que puedan presentar dos lugares en lo referente a recursos, a infraestructuras, a mercado laboral, a paisaje o a patrimonio cultural, por poner sólo unos ejemplos, se convierten ahora en muy significativas.

'Pensar globalmente y actuar localmente' se ha convertido en una consigna fundamental que ya no sólo satisface a los grupos ecologistas, sino también a las empresas multinacionales, a los planificadores de las ciudades y de las regiones y a los líderes políticos. En efecto, "lo local y lo global se entrecruzan y forman una red en la que ambos elementos se transforman como resultado de sus mismas interconexiones. La globalización se expresa a través de la tensión entre las fuerzas de la comunidad global y las de la particularidad cultural" (GUIBERNAU, 1996, p.146). Más aún: el lugar actúa a modo de vínculo, de punto de contacto e interacción entre los fenómenos mundiales y la experiencia individual. En efecto, GLOCAL (de GLObal y

loCAL) se ha convertido en un neologismo de moda.

Sea cual sea el punto de vista escogido, lo cierto es que el lugar reaparece hoy con fuerza y vigor. La gente afirma, cada vez con más insistencia y de forma más organizada, sus raíces históricas, culturales, religiosas, étnicas y territoriales. Se reafirma, en otras palabras, en sus identidades singulares. Como indica Manuel Castells (1998), los movimientos sociales que cuestionan la globalización son, fundamentalmente, movimientos basados en la identidad, que defienden sus lugares ante la nueva lógica de los espacios sin lugares, de los espacios de flujos propios de la era informacional en la que ya nos hallamos inmersos.

Reclaman su memoria histórica, la pervivencia de sus valores y el derecho a preservar su propia concepción del espacio y del tiempo. La sensación de indefensión, de impotencia, de inseguridad ante este nuevo contexto de globalización e internacionalización de los fenómenos sociales, culturales, políticos y económicos provoca un retorno a los micro territorios, a las micro sociedades, al lugar en definitiva. La necesidad de sentirse identificado con un espacio determinado es ahora, de nuevo, sentida con intensidad, sin que ello signifique volver inevitablemente a formas premodernas de identidad territorial.

Si uno atiende a este fenómeno de retorno al lugar que acabamos de describir y lo añade al potente y coyuntural neodesarrollismo en el que el país está inmerso desde hace unos años, no debería extrañarse del malestar territorial que nos afecta y que, curiosamente, se vehicula, se 'somatiza', en la mayoría de los casos, a través del paisaje.

\section{HACIA UNA NUEVA CULTURA DEL PAISAJE}

Después de todo lo dicho, parece evidente que los poderes públicos tienen sobre la mesa una cuestión por resolver: una creciente conflictividad territorial, vinculada a la pérdida de una identidad paisajística propia, debida a procesos de transformación territorial no consensuados ni participados y, en la mayoría de los casos, mal explicados. Parece evidente, pues, que habrá que mejorar la gobernabilidad de las políticas territoriales, lo que implica contemplar los procesos no estructurados de participación ciudadana y reflexionar a fondo sobre los procesos participativos ya existentes, incidiendo mucho más en la cooperación, la participación y la gestión concertada. Urge una nueva cultura del paisaje en el marco de una nueva cultura territorial que evite "legar a las generaciones venideras una España desfigurada, plagada de riesgos y repleta de exasperaciones cotidianas, de desequilibrios territoriales, de procesos segregadores y de deterioro irreversible de elementos culturales, simbólicos y patrimoniales", como reza el "Manifiesto por una nueva cultura del territorio", presentado a mediados de 2006 en el Círculo de Bellas Artes de Madrid y firmado 
por centenares de expertos y profesionales preocupados por la deriva que ha tomado el urbanismo y la ordenación del territorio en España en estos últimos años.

No es ninguna quimera plantearse la consideración del sentido de lugar en el planeamiento territorial de carácter paisajístico. De hecho, en estos últimos años se han desarrollado propuestas de protección, ordenación y gestión del paisaje que aspiran a preservar el sentido de lugar y a reducir, por tanto, la conflictividad territorial aludida en este capítulo.

Todas ellas comparten un requisito fundamental: la participación ciudadana. Sin ella, es imposible avanzar hacia una nueva cultura territorial basada en una gestión sostenible de los recursos naturales y patrimoniales y en un nuevo tratamiento y consideración del paisaje en su conjunto. Sólo a través de auténticos procesos participativos es posible transformar el territorio y sus paisajes sin que aquél pierda su discurso y éstos su imaginario. El Convenio Europeo del Paisaje, que, por fin, España ha ratificado, insiste en la importancia que tiene la participación de los ciudadanos y de los agentes económicos en la planificación del paisaje. Dicho Convenio afirma que es necesario "establecer procedimientos para la participación del público, las autoridades locales y regionales y otras partes interesadas en la formulación y aplicación de las políticas en materia de paisaje". Y por ello propone incidir en los objetivos de calidad paisajista entendidos como "la formulación, por parte de las autoridades públicas competentes, de las aspiraciones de las poblaciones en lo que concierne a las características paisajísticas de su entorno". Se trata, por tanto, de integrar la participación pública como herramienta para la implicación y corresponsabilidad de la sociedad en la gestión y planificación del paisaje. La participación debería ser el mecanismo fundamental a través del cual los ciudadanos se implican en el diseño del paisaje que quieren y contribuyen a través de ella a decidir las políticas que se aplicarán.

Andamos escasos de sensibilidad paisajística. Deberíamos dar la vuelta a una frase que Julien Gracq escribió hace unos años: 'tantas manos para transformar este mundo, y tan pocas miradas para contemplarlo'. Es necesario impulsar una sensibilidad, una cultura, una conciencia de paisaje que nos permita ser capaces de disfrutar mirando el paisaje, como reclamaba el escritor y geógrafo francés. Hemos conseguido, con mucho esfuerzo, una cierta conciencia ambiental, que ha penetrado, con más o menos convencimiento, en las capas dirigentes del país y también en amplias capas de la población. Esta conciencia ambiental ha permitido proteger, a través de figuras jurídicas diversas, determinadas porciones del territorio especialmente valiosas por su riqueza ecológica. Ahora es necesario ir más allá y superar esta visión protectora del territorio en forma de manchas de aceite; es decir, espacios naturales protegidos dispersos por el territorio y, en el mejor de los casos, conectados por corredores biológicos. Es necesario imbuirnos de una conciencia de paisaje similar a la conciencia ambiental descrita que nos permita disfrutar de la simple contemplación de los paisajes que nos rodean, no para atraer más turistas, no como resultado de alguna acción especial derivada de un ambicioso plan estratégico, sino, simplemente, porque es un hecho mil veces demostrado que un entorno físico atractivo, agradable y estéticamente armónico genera una agradable sensación de bienestar, que incrementa de manera notable la calidad de vida de los ciudadanos. Esto es, ni más ni menos, lo que nos recuerda el Convenio Europeo del Paisaje cuando afirma que "el paisaje es un elemento importante de la calidad de vida de las poblaciones en los medios urbanos y rurales, en las zonas degradadas y de gran calidad, en los espacios de reconocida belleza excepcional y en los más cotidianos". Se mire por donde se mire, este Convenio es la plasmación más palmaria de la cada vez mayor interacción entre paisaje, territorio y sociedad civil.

\section{REFERENCIAS BIBLIOGRÁFICAS}

ALFAMA, Eva; et al. Per una nova cultura del territori? Barcelona: Icària, 2007. BERQUE, Augustin. Médiance de milieux en paysages. Montpellier: Reclus, 1990. 
BERQUE, Augustin. Les raisons du paysage. Paris: Hazan, 1995.

BUTTIMER, Anne. Sociedad y medio en la tradición geográfica francesa. Barcelona: OikosTau, 1980. CASTELLS, Manuel. La era de la información: economía, sociedad y cultura. 3 Vols. Madrid: Alianza Editorial, 1998.

COLECTIVO DE GEÓGRAFOS (org.) Eliseo Reclus. La geografía al servicio de la vida. Barcelona: Editorial 71/2, 1980.

GARCIA, Xavier. Catalunya es revolta. Barcelona: Angle Editorial, 2003.

GUIBERNAU, Montserrat. Los nacionalismos. Barcelona: Ariel, 1996.

LOWENTHAL, David. El pasado es un país extraño. Madrid: Akal, 1998.

LUGINBHUL, Yves. Paysages. Textes et représentations du paysage du siècle des Lumières à nos jours. Paris: La Manufacture, 1989.

LYNCH, Kevin. The Image of the City. Cambridge: The Massachussetts Institute of Technology Press, 1960. MATLESS, David. Landscape and Englishness. London: Reaktion Books, 1998.

NEL.LO, Oriol. Aquí, no! Els conflictes territorials a Catalunya. Barcelona: Empúries y Càtedra de Geografia i Pensament Territorial de la Universitat de Girona, 2003.

NOGUÉ, Joan. Nacionalismo, territorio y paisaje en Cataluña, in: ORTEGA CANTERO, Nicolás. Paisaje, memoria histórica e identidad nacional. Madrid: Universidad Autónoma de Madrid y Fundación Duques de Soria, 2005. p.147-169.

NOGUÉ, Joan. La necessària revisió dels paisatges de referência. Nexus, 36, 2006. p.36-49.

NOGUÉ, Joan (org.) La construcción social del paisaje. Madrid: Biblioteca Nueva, 2007.

NOGUÉ, Joan; ROMERO, Joan (orgs.) Las otras geografias. València: Tirant lo Blanch, 2007.

12 NORA, Pierre (ed.) Les Lieux de mémoire. Paris: Gallimard, 1984-1992.

ORTEGA CANTERO, Nicolás. Naturaleza y cultura en la visión geográfica moderna del paisaje. In: ORTEGA CANTERO, Nicolás (org.). Naturaleza y cultura del paisaje. Madrid: Ediciones de la Universidad Autónoma de Madrid, 2004. p.9-35.

ROGER, Alain. Breve tratado del paisaje. Madrid: Biblioteca Nueva, 2007.

TURRI, Eugenio. Semiologia del paesaggio italiano. Milano: Longanesi, 1979.

Trabalho enviado em maio de 2011

Trabalho aceito em julho de 2011 